\title{
Underwater Explosive Welding of Tin and Aluminium Plates
}

\author{
Satyanarayan ${ }^{1, a^{*}}$, Shigeru Tanaka ${ }^{2, b}$ and Kazuyuki Hokamoto ${ }^{3, c}$ \\ ${ }^{1}$ Department of Mechanical Engineering, Alva's Institute of Engineering and Technology, Moodbidri \\ - 574225, India \\ ${ }^{2}$ Institute of Pulsed Power Science, Kumamoto University, Kumamoto, 8608555, Japan \\ ${ }^{3}$ Institute of Pulsed Power Science, Kumamoto University, Kumamoto, 8608555, Japan \\ asatyan.nitk@gmail.com, btanaka@mech.kumamoto-u.ac.jp, \\ chokamoto@mech.kumamoto-u.ac.jp
}

\begin{abstract}
Keywords: Underwater Shockwave, Al/Sn, Explosive Welding, interface, Wavy Morphology
\end{abstract}

\begin{abstract}
In the present study, underwater explosive welding of commercial pure Sn and Al plates was attempted. Distance between the explosive and the center of the sample was varied to change the pressure applied to the plates to be welded. Evolution of interfacial microstructures at the welded Sn/Al joints was assessed. An increase in the distance between explosive and the sample exhibited decrease in the formation of wavy morphology at the interface. Cross-sectional interfacial microstructures clearly indicated that, Sn and Al plates can be joined successfully using underwater explosive welding technique.
\end{abstract}

\section{Introduction}

The Explosive welding (EXW) is a solid state process used for the joining (metallurgical) of similar or dissimilar a metal which is regarded as one of the most widely employed materials processing technique [1]. The EXW is generally performed in an open atmosphere. However, it is reported that conventional explosive welding always poses a problem for welding of materials, particularly for thin metal plate (below $1 \mathrm{~mm}$ thickness) as well as brittle materials such as amorphous ribbon/ceramics and fusing of tungsten $(\mathrm{W}) / \mathrm{Cu}[2,3]$. Literature suggested that by using underwater explosive welding a significant decrease in kinetic energy (K.E) loss at the interface of flyer plate and base plate can be achieved [4-6]. In this method, water acts as a pressure transmitting medium. The underwater shock waves prevent the distortion of the welded joint and ensure the integrity of the joints. Hence, underwater explosive welding is regarded as one of the best and novel welding techniques [7, 8]. It reported that, $\mathrm{Al} / \mathrm{Steel}, \mathrm{Al} / \mathrm{Cu}, \mathrm{Sn} / \mathrm{Cu}$ and $\mathrm{Cu} /$ Stainless Steel combinations of materials are the most essential in the electrical engineering and among these $\mathrm{Al} / \mathrm{Cu}$ joints are widely used as electrical connectors in many industries because of their good corrosion resistance and electrical conductivity [9]. Although numerous investigations on explosive welding of various metal combinations were conducted by the researchers [9-12] welding and cladding of Sn and Al using this technique have not been paid attention. Sn based solder alloys are electrically connected with metallic components (most notably the $\mathrm{Cu}$ conductors) in the electronic device. However there is no solder alloy in electronic applications which operates with $\mathrm{Al}$ in the same way that ordinary solders operate with copper. Because $\mathrm{Al}$ does not alloy readily with solders, moreover the $\mathrm{Al}$ surface is covered with a thin invisible coating of aluminium oxide. Thin oxide film makes it difficult to join dissimilar materials [13].

Thus, the aim of current study is to make an attempt to fusing of Sn and Al plates using underwater explosive welding method. Further, evolution of interfacial microstructures between welded $\mathrm{Sn} / \mathrm{Al}$ joint is investigated. 


\section{Experimental}

The commercial high purity Sn $(0.5 \mathrm{~mm} \times 100 \mathrm{~mm} \times 100 \mathrm{~mm})$ and $\mathrm{Al}(5 \mathrm{~mm} \times 100 \mathrm{~mm} \times 100 \mathrm{~mm})$ plates procured from Nilaco corporation, Japan were used in the present study. The procured Sn plate was sectioned into small plates having a dimension of $0.5 \mathrm{~mm}$ thick $\times 50 \mathrm{~mm}$ length $\times 50 \mathrm{~mm}$ width and Al plate of $5 \mathrm{~mm} \times 50 \mathrm{~mm} \times 50 \mathrm{~mm}$. Underwater explosion welding experiments with an inclined setup were performed to weld Sn and Al plates. A stand-off distance (SOD) between the flyer plate $\mathrm{Sn}$ and base plate $\mathrm{Al}$ was set to $0.2 \mathrm{~mm}$ by placing $0.2 \mathrm{~mm}$ thick aluminium plate as spacer between the plates. The inclination angle $(\propto)$ between the plates was set to $20^{\circ}$ to control the collision angle and the velocity. A stainless steel (SUS 304, $0.1 \mathrm{~mm} \times 50 \mathrm{~mm} \times 50 \mathrm{~mm}$ ) was used as cover plate above the flyer plate to eliminate cracks between the joints. An inclined layer of SEP explosive (detonation velocity of $7 \mathrm{~km} / \mathrm{s}$, density $1300 \mathrm{~kg} / \mathrm{m}^{3}$ ) was bonded to Polymethyl Methacrylate (PMMA) plate and positioned above the flyer plate. The SEP explosive was procured from Kayaku Japan Co, Ltd, Japan. The distance between explosive and the center of the sample (d) were set at 30 and $60 \mathrm{~mm}$. A mild steel anvil was positioned below the sample to ensure the sample flatness and to adjust its height. Entire setup was kept inside PMMA container which contained water. Fig. 1 shows the schematic diagram of underwater shockwave explosion welding technique with weldable conditions.
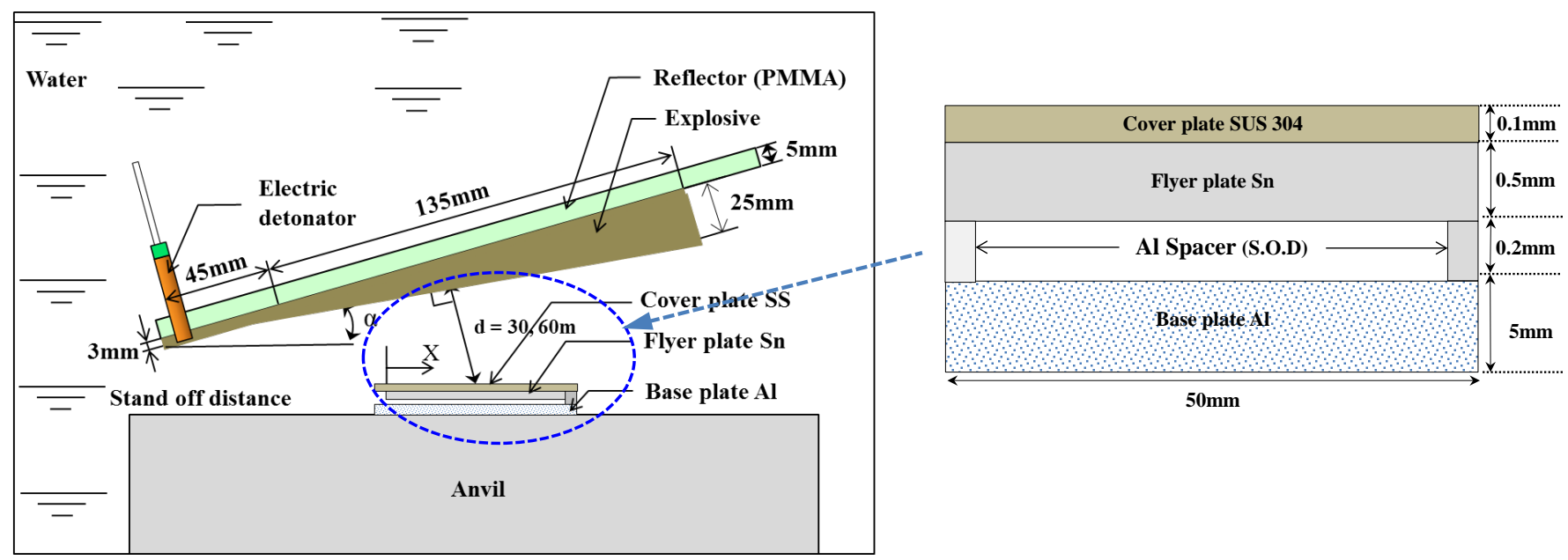

Fig. 1: Schematic outline of explosive welding using underwater shock wave technique.

Welded Sn/Al plates were sectioned along the direction of wave propagation using shear cutting machine (Aizawa, AST-612). Sectioned samples were polished using SiC papers of different grit sizes (400-2000 mesh number) using emery paper disc polishing machine (Velnus, Asahikase make). The final polishing was carried out on a disc polisher (Struers labpol - 1) using silica liquid lubricant. Interfacial region of $\mathrm{Sn} / \mathrm{Al}$ joint cut at the center parallel to the detonation direction was micro-examined using an optical microscope (Nikon LM 2) and scanning electron microscope (JEOL JSM 6510A).

\section{Results and discussion}

Underwater explosive bonded Sn/Al plates at varied distance of the explosive from the center of the sample are shown in Fig. 2. As the detonation initiated, chemical reaction of explosive at high rate generated the shockwaves in the surrounding water. These shockwaves propagated through the 
water and accelerated the Sn plate (flyer) to impact the Al plate (base). Due to the collision (at higher rate), a strong metallurgical bond between $\mathrm{Sn}$ and $\mathrm{Al}$ was occurred.

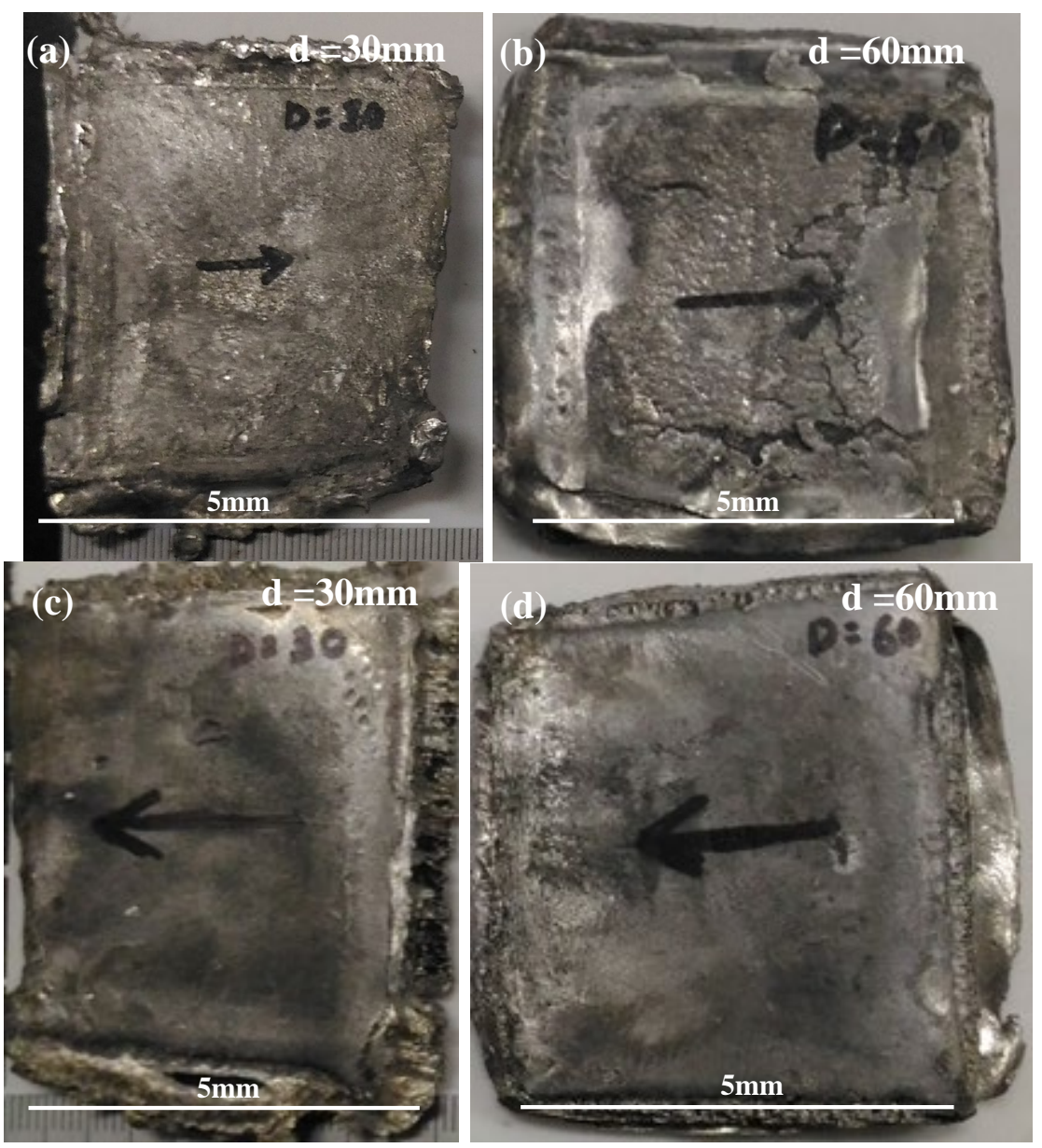

Fig. 2: Explosive welded (underwater) Sn/Alu samples at (a) $d=30 \mathrm{~mm}$ front view (c) $d=30 \mathrm{~mm}$ back view (b) $d=60 \mathrm{~mm}$ front view (d) $d=60 \mathrm{~mm}$ back view

If the distance between explosive and the center of the sample is kept low, collision takes place before the flyer Sn plate could reach the maximum velocity. Further, at higher distance of explosive from the sample, the velocity drops to a lower value at the time of collision $[8,14]$. The optical microstructures of cross section along welding direction (horizontal positions) for the samples welded at $\mathrm{d}=30 \mathrm{~mm}$ and $60 \mathrm{~mm}$ are shown in Fig. 3 and 4.

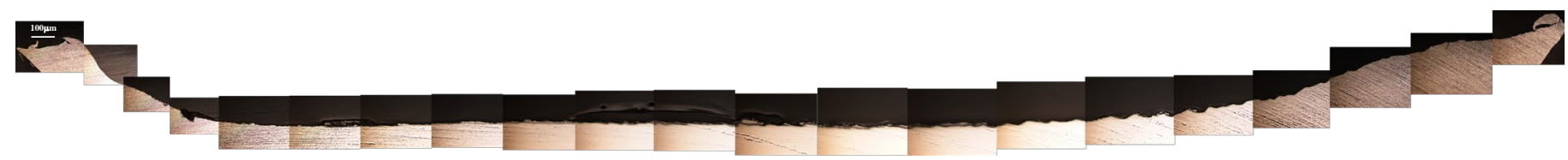

Fig 3: Microstructures of cross section along the welding direction (horizontal positions) of welded $S n / A l$ plates at $d=30 \mathrm{~mm}$. 
Fig 4 : Microstructures of cross section along the welding direction (horizontal positions) of welded $\mathrm{Sn} / \mathrm{Al}$ plates at $d=60 \mathrm{~mm}$.

Interfacial microstructures (at higher magnification) of welded $\mathrm{Sn} / \mathrm{Al}$ joints at varied water distance are shown in Fig. 5 and 6. Results indicated that pure $\mathrm{Sn}$ and $\mathrm{Al}$ can be successfully welded/joined using underwater explosive welding method. During explosive welding process, kinetic energy (K.E) of the flyer plate Sn was transformed to potential by colliding with the base plate Al. This resulted in plastic deformation at the interface of $\mathrm{Sn}$ and Al plates. Due to higher intensive plastic deformation at $\mathrm{d}=30 \mathrm{~mm}$, a wavy morphology (Fig. 5) was formed at the interface, which swept the surface layers of $\mathrm{Sn}$ over Al base plate. However, the kinetic energy of flying plate, energy shockwave and plastic flow was found to be minimum at $\mathrm{d}=60 \mathrm{~mm}$ due to which small waves in smaller wavelength (Fig. 6) were observed at the $\mathrm{Sn} / \mathrm{Al}$ interface.

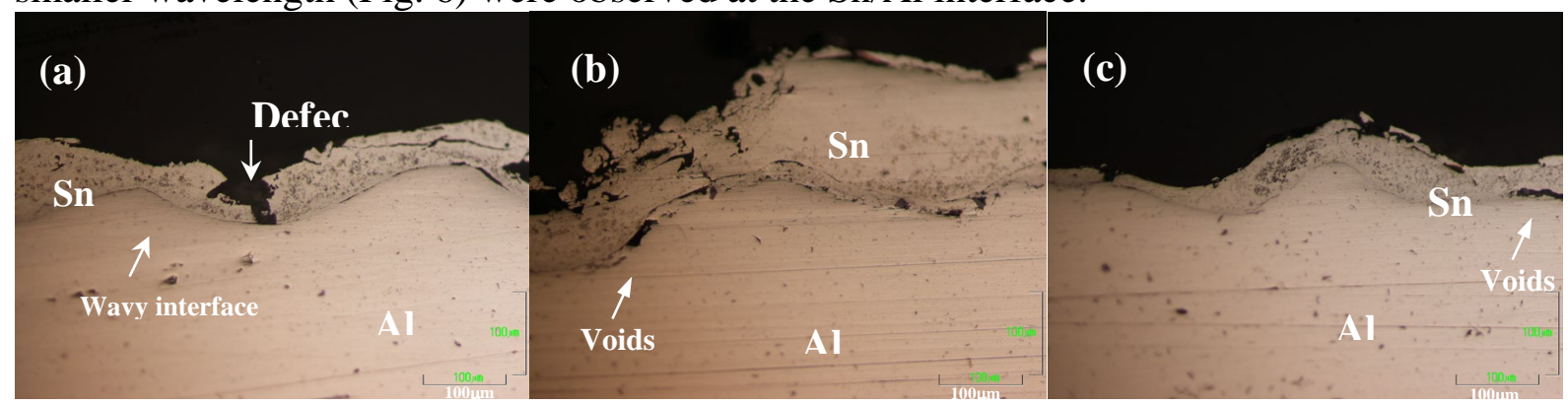

Fig. 5: Optical microstructures of explosive welded Sn/Al joints $(d=30 \mathrm{~mm})$ at different locations

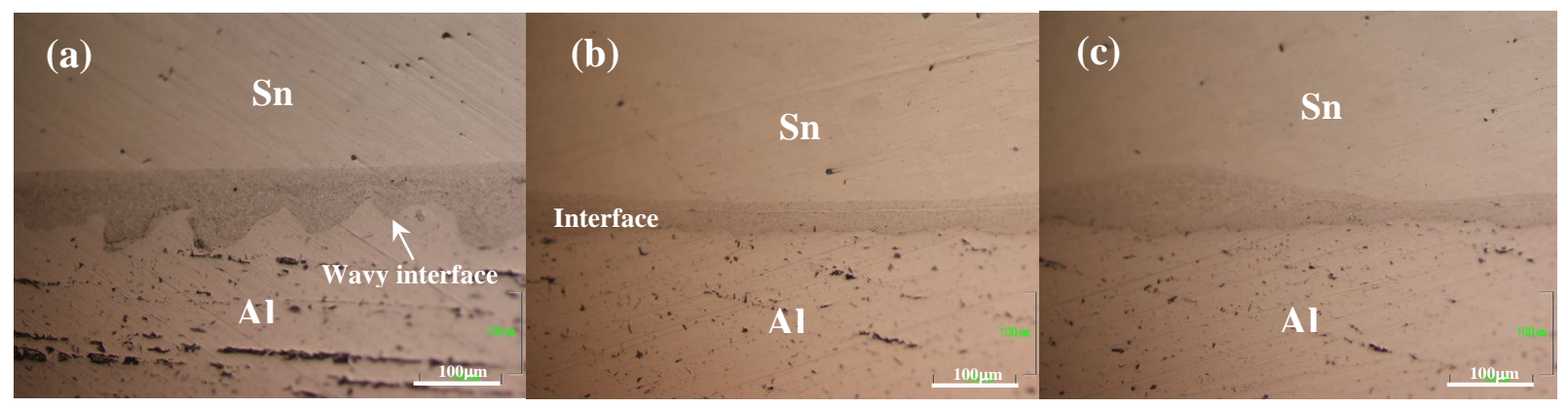

Fig. 6: Optical microstructures of explosive welded $\mathrm{Sn} / \mathrm{Al}$ joints (d=60mm) at different locations

At the interface of $\mathrm{Sn} / \mathrm{Al}$ plates welded at $\mathrm{d}=30 \mathrm{~mm}$ other than large waves, cracks and voids were formed because, the energy shockwave was more, and loss of kinetic energy of flyer plate was high compared to $d=60 \mathrm{~mm}$. Microstructures indicated that the welding was not successful at interface of Sn/Al joints welded at $\mathrm{d}=30 \mathrm{~mm}$. However, a good bonding was observed at interface of Sn/Al joints welded at $d=60 \mathrm{~mm}$.

\section{Conclusion}

Based on the results and discussion the following conclusions are drawn.

$\mathrm{Sn}$ and Al plates can be successfully bonded using underwater explosive welding method. 
The size and morphology of wavy interface decreased with increase in the distance between the explosive and the center of the sample

The interface of samples welded at $\mathrm{d}=30 \mathrm{~mm}$ associated with the cracks and voids, whereas samples welded at $\mathrm{d}=60 \mathrm{~mm}$ was found to be free defects.

\section{References}

[1] B Crossland, J.D.Williams, Explosive welding. Metall. Rev. 15 (1), (1970) 79-100.

[2] H. Iyama, A. Kira, M. Fujita, S. Kubota, K. Hokamoto, S Itoh, An investigation on underwater explosive bonding process. J. Pressure Vessel Technol. Trans. ASME 123 (4) (2001) 486-92. https://doi.org/10.1115/1.1388007

[3] P. Manikandan, J.O. Lee, K. Mizumachi, A. Mori, K. Raghukandan, K. Hokamoto Underwater explosive welding of thin tungsten foils and copper. J. Nucl. Phys.Mater. Sci. Radiat. Appl. 418 (13) (201) 281-285. https://doi.org/10.1016/j.jnucmat.2011.07.013

[4] K. Hokamoto, M. Fujita, M., H. Shimokawa, Explosive welding of a thin metallic plate onto a ceramic plate using underwater shock wave. Rev. High Press. Sci. Technol. 7 (1998) 921-923. https://doi.org/10.4131/jshpreview.7.921

[5] A. Mori, K. Hokamoto, M. Fujita, Characteristics of the new explosive welding technique using underwater shock wave-Based on numerical analysis. Mater. Sci. Forum 465 (2004) 307-312. https://doi.org/10.4028/www.scientific.net/msf.465-466.307

[6] A. Mori, K. Hokamoto, M. Fujita, Controlling shock pressure distribution for explosive welding using underwater shockwave. J. JSTP 47 (542) (2006) 195-199 in Japanese. https://doi.org/10.9773/sosei.47.195

[7] D. Mori, K. Ryuta, S. Konishi, Y. Morizono, K. Hokamoto, K Underwater explosive welding of tungsten to reduced-activation ferritic steel F82H. Fusion Eng. Des. 89 (2014) 1086-1090. https://doi.org/10.1016/j.fusengdes.2013.12.038

[8] Satyanarayan, S. Tanaka, A. Mori, K. Hokamoto, K., Welding of Sn and Cu plates using controlled underwater shock wave. J. Mater. Process Technol. 245 (2017) 300-308. https://doi.org/10.1016/j.jmatprotec.2017.02.030

[9] K. Paul, V. Cyril, M. Jukka, S. Raimo, Factors influencing Al-Cu weldproperties by intermetallic compound formation. IJMME 10 (2015) 10.

[10] M. Acarer, B. Gulenc, F. Findik, The influence of some factors on Steel/Steelbonding quality on their characteristics of explosive welding joints. J. Mater.Sci. 39 (21) (2004) 6457-66.

[11] A. Durgutlu, B. Gulenc, F. Findik, Examination of copper/stainless steel joints formed by explosive welding. Mater. Des. $26 \quad$ (6) $\quad$ (2005) 497-507. https://doi.org/10.1023/b:jmsc.0000044883.33007.20

[12] F. Findik, Recent developments in explosive welding. Mater. Des. 32 (2011.)1081-1093. https://doi.org/10.1016/j.matdes.2010.10.017

[13] Satyanarayan and K N Prabhu., 2011. Wetting behaviour and interfacial microstructure of SnAg-Zn solder alloys on nickel coated aluminium substrates, Materials Science and Technology, 27:7, 1157-1162. https://doi.org/10.1179/026708310x12815992418337

[14] Satyanarayan, A. Mori, M. Nishi, and K. Hokamoto Underwater shock wave weldability window for Sn-Cu plates. Journal of Materials Processing Technology, 267 (2019) pp.152-158. https://doi.org/10.1016/j.jmatprotec.2018.11.044 